\title{
Using Action Learning And Critical Thinking Tools To Make Changes In Higher Education
}

Janice Witt Smith, Ph.D., Winston-Salem State University, USA D. Kathy Stitts, Ph.D., Winston-Salem State University, USA

\begin{abstract}
As the reported institution increased admission requirements, added master's and doctoral programs, and revised its strategic thrust, greater emphasis was placed on assessing student learning outcomes and whether the "treatment" of education has had a measurable impact. Consistent with Smith and Clark (2010), we implemented an action learning approach and integrated critical thinking concepts in instructional delivery for an undergraduate human resource management (HR) capstone course and examined the process used to changing the general education curriculum and advising model through those same lenses. Keys to success in both arenas depend on faculty engagement and interest, willingness to be in a continuous improvement mode and their high level of involvement and trust in the goals and process. Additionally faculty's comfort with receiving and incorporating feedback from students in realtime, particularly if developmental feedback, without reacting punitively, is critical in maintaining student interest and involvement in the course laden with action-learning and critical-thinking activities. Student engagement, interest and willingness to be in a continuous improvement mode increase with faculty receptivity to feedback and accessibility for interaction outside of the classroom.
\end{abstract}

Keywords: Action Learning; Critical Thinking; Change Management; Feedback; Engagement; Curriculum; Advising; Faculty; HR; Human Resource Management

\section{INTRODUCTION}

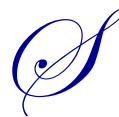

imilar to other businesses, whether for profit or not-for profit, academic institutions are also impacted by the fluctuations of the economic environment. What happens to their primary customers (their students and their families, the employers who hire their students, the state governments who provide funding, their own employees, and the like) has a significant and direct impact on them. In this current environment, there are typically fewer jobs available to graduates and increased pressure that one's own students are well qualified and prepared for both those limited open positions and graduate programs.

In addition, hiring businesses are experiencing challenges and uncertainties that they have never faced before. They are, therefore, looking for graduates who have the communication and critical thinking skills to help them in solving real-world, challenging, and complex organizational problems in a global competitive environment. This integrated economic environment is not easily negotiated, and insulated thinking has led to the demise of many previously successful businesses. Successful educational institutions must have a paradigm shift in the way they meet the needs of their constituents or find themselves irrelevant and obsolete.

A Society for Human Resource Management report (SHRM 2007), and reaffirmed by other anecdotal reports since, found that when graduates entered the workforce, they had deficiencies among graduates in communication and critical thinking skills. The report recommended that applied skills such as critical thinking and problem solving must be taught in academic, content-rich courses, rather than as standalone modules. This report 
further indicated that there is a bias in college-centered teaching toward rote memorization rather than practical application. Finally, despite global competitiveness being a critical factor in educating and developing U.S. workers, their data indicated that the systems and infrastructure needed to do so in the U.S. is sorely lacking. Sadly, this report is consistent with other data that indicates that the U.S. has fallen behind in the educational sector - in math and science. Indeed, the data show that as a country the United States is no longer the world knowledge leader and even has a shortage of skilled labor.

The global economic meltdown, shortage of skilled labor in the United States, and other data indicate that there needs to be paradigm shift in the way that U.S. students are educated, particularly in the realm of critical thinking and problem solving skills. Students not only need to learn and practice them, but they need to see them in action. We employ an action research approach as seasoned faculty use tools and techniques to teach and enhance critical thinking in their classroom in a capstone HR class that has a national assessment. In addition, we couple that approach using action learning techniques. A second prong of this research is the application of action research and critical thinking in the process of revising the general education curriculum and making changes in the way we look at education and advise our students.

\section{RESEARCH QUESTIONS AND RATIONALE}

(1) In what ways are action learning and critical thinking tools and techniques intertwined and applicable in resolving a problem?

(2) To what extent are academicians prepared to change the way we view education to meet the changing business and economic environment to ensure that our graduates make a difference in the world they are expected to change?

(3) What types of interventions are successful in engaging institutional learners in making sustainable changes that impact the academic environment?

\section{CHANGE MANAGEMENT}

\section{Forces for Change}

Robbins and Judge (2009) suggest there are at least six forces for change that have the potential to impact an organization: (1) the nature of the workforce; (2 technology; (3) economic shocks; (4) competition; (5) social trends; and (6) world politics.

The SHRM reported talked about the deficiencies in the college-educated workforce. While a mandate may exist that significant change occur within an environment, the environment itself (i.e., the culture) must be ready for the change; individuals must be prepared for the transition; resistance to the change must be addressed; and the change must be managed. We have made the argument that external forces are extended great pressure on higher education to change. Indeed, the academic environment itself is pressured through budget cuts and shortfalls; low enrollment programs; persistence, retention and graduation rates; competition for high-quality faculty and students; and branding itself to make changes in the ways it does business. This institution of interest in this study has the additional challenge of having two other university system schools within 30 miles of it. More generally, the proliferation of for-profit educational institutions which place less emphasis on accreditation and the competition from distance learning programs competing on line from worldwide universities, erase the previous "geographical advantage" of brick-and-mortar institutions.

\section{Resistance to Change}

Audia and Brion (2007) found that both organizations and their members resist change and will latch onto whatever data they can find that tells them they do not need to change. . Another critical part of this process is that the organization must identify the sources of possible resistance to change prior to the change and alemploy those tactics prior to the planned change. This resistance does not necessary surface in standard ways. It can be overt, implicit, immediate or deferred. Additionally, this resistance may be at the individual level (individual faculty members) and at the organizational level (includes departments who want to protect their classes, at the school level and/or at the university level). 
Possible individual barriers to change are habit, security, fear of the unknown, and economic factors. Institutional sources of resistance include threat to expertise of specialized group; possible "overthrow" of existing power structure; structural inertia; limit $4 \mathrm{~d}$ focus of change; and group inertia. There are also many politics involved in change efforts and initiatives which organizations must deal and should never overlook. There are likely to be power struggles and jockeying for position and the fallout may threaten or destabilize individuals at lower levels in the organization.

Seven tools that Kotter and Schlesinger (1979) identified to overcome resistance to change are through: (1) education and communication-help others see logic of change and fights effects of miscommunication; (2) participation of those who are resistant - it is difficult for individuals to resist a change where they were part of the decision making process; (3) building support and commitment; (4) implementing changes fairly; (5) manipulating and cooptation - credibility drops to zero when this is revealed; (6) selecting people who accept change; and (7) coercion - application of direct threats or force on resisters. This is not a sustainable strategy.

Kotter $(1995,1996)$ created an eight-step plan for implementing the change that remedied the failures that managers made when trying to initiate the change. Basically there needed to be a sense of urgency established by creating a compelling reason for the change; create a coalition with enough power to lead the change; create new vision to direct change and strategies to achieve vision; communicate vision throughout organization; empower others to act on vision by removing barriers and encourage risk taking and creative problem solving; plan for create, and reward shot-term "wins" that move organization toward new vision; consolidate improvements, reassess changes and make necessary adjustments to new program; reinforce changes by linking relationship between new behaviors and organizational success.

Festinger defined cognitive dissonance as "any incompatibility between two or more attitudes or between behavior and attitudes. He argued that if an individual experiences any type of inconsistency between attitudes and beliefs that (s)he feels uncomfortable and tries to resolve that inconsistency, seeking a stable state. They will either alter either the attitude or behavior or develop a rationalization for the discrepancy. Moderating factors impact whether or not the individual is motivated to resolve the dissonance to return to a stable state. The desire to reduce the dissonance depends on the importance of the dissonance to the individual and the amount of influence that the individual believes he has over the elements creating it, and the reward associated with resolving the dissonance.

\section{CRITICAL THINKING}

Critical thinking is the mental process of actively and skillfully conceptualizing, applying, analyzing, synthesizing, and evaluating information to reach an answer or conclusion. In short, it is the "...purposeful, selfregulatory judgment which results in interpretation, analysis, evaluation, and inference, as well as explanation of the evidential, conceptual, methodological, criteriological, or contextual considerations upon which that judgment is based. (Facione, 1998)

The three important aspects of Critical Thinking are quick thinking (practice thinking on one's feet); creative thinking (thinking "outside of the box" - boundaries, stated parameters); and analytical thinking (solving problems logically, using scientific approach of defining problem, generating list of possible solutions, selecting solution, implementing, evaluating and making adjustments). Facione (1990) was one of the first scholars in the field of philosophy to establish a consensus definition for critical thinking. Facione and his 46 experts described critical thinking as "habitually inquisitive, flexible, orderly in complex matters, and diligent in seeking relevant information." Scriven and Paul (2001:1) further expanded the definition to include: "the intellectually disciplined process of actively and skillfully conceptualizing, applying, analyzing, synthesizing, and or evaluating information gathered from, or generated by, observation, experience, reflection, reasoning or communication, as a guide to belief and action." Facione (2006) found that the interpretation, analysis, evaluation, inference, explanation and self-regulation were the cognitive skills at the core of critical thinking. Shakira (2007:42) argues that critical thinking skills are necessary for enabling students "to deal effectively with social, scientific, and practical problems.

Khojasteh and Smith (2010) discussed the use of critical thinking in classrooms and emphasized the criticality of faculty comfort in engaging students in critical thinking activities. This is consistent with Tempelaar's 
(2006) finding that many teachers struggle with engaging students in critical thinking activities. Consistent with these findings, other researchers (Bartlett, 2002; Rippin, Booth, Bowie \& Jordan, 2002) found that students seldom use critical thinking skills in their evaluation and solving of real world, complex problems. Celuch and Slama (1999) found that traditional instructional methods are focused on short-term knowledge and lack the ability to apply that knowledge in new situations, and as such are inadequate to teach critical thinking because of their focus on rote memorization and lecture. Broadbear (2003:7) argued that critical thinking activities should include four critical elements: (1) "ill-structured problems; (2) criteria for assessing thinking, (3) student assessment of thinking; and (4) improvement of thinking."

Critical thinkers have the ability to think critically and to argue logically. Well educated students should have an opportunity to (1) think freely and to effectively and respectfully challenge other student's ideas with their own. Arguments have been made by Yang (2008) and others (Barnett, 2004; Facione, 2007; Garrison et al., 2001; Yang et al., 2005; Yeh, 2006), that the educational experiences of both undergraduate and graduate students should include their development of critical thinking skills.

\section{Student Receptivity}

For students to be most receptive to critical thinking tools and techniques, the student must be motivated to learn; have an acceptance of controversies; have a desire for discovery through a spirit of openness to learn; have a truth-seeking mentality; have an aptitude for self-directed learning; and an attitude and willingness to engage in critical thinking. A professor's aptitude should include in-depth knowledge of subject; truth-seeking mindset; inclination to use CT; and acceptance of controversies.

\section{Characteristics of Critical Thinkers}

Toastmasters International (2005) identified several characteristics of critical thinkers: (1) They question what they read and hear; (2) they consider information in qualitatively different ways; and (3) Once they have assessed the situation, challenge or concern, they are able to reach and explain their conclusion. Among the other characteristics that critical thinkers should have are asking pertinent and germane questions; evaluating statements and arguments made by self and others; being curious about world and the material/problem; having an interest in finding new solutions; looking for evidence to supporting assumptions and beliefs or to substantiate thinking; willing to examine opinions, assumptions and beliefs and evaluating them against facts; and communicating effectively with others in figuring out solutions to complex problems (Scriven and Paul, 2007).

\section{Underlying "thinking" skills in discipline}

Bonwell (2012), described by the editor of The National Teaching \& Learning Forum as one of the earliest and best writers on active learning, examined a discipline-specific approach to critical thinking by first asking the question, "What are the underlying processes or thinking skills in your discipline?" His self reflection (over 30-year career as a faculty member and Emeritus Professor) and conversations with critical others suggested that the assignments and tests that faculty give to their students are the best indicators of the thinking skills utilized in each of the disciplines.

Examples of thinking skills that a discipline might emphasize are: identifying key definitions; identifying ambiguity; formulating questions for clarification; defining the central issue or problem; recognizing patterns; determining the credibility of a source; summarizing information; classifying information into groups; placing information in to sequential groups; and identifying relationships between elements using comparing and contrasting or cause and effect Bonwell (2012). 


\section{ACTION LEARNING/ACTION RESEARCH}

\section{Action Learning/Action Research}

Marquadt (1999:4) defines "Action learning is both a process and a powerful program that involves a small group of people solving real problems while at the same time focusing on what they are learning and how their learning can benefit each group member and the organization as a whole". In our first case study, we apply action learning techniques and critical thinking tools in the classroom and how it is impacted by what occurs both in the internal and external environment, through observation, experience and feedback, while simultaneously making adjustments in and stabilizing the course to facilitate a better learning experience for the students and a better working environment for the faculty member.

Action research can also be defined as a change process which is based on the systematic collection of data and then a change action is selected based on what that analyzed data indicate (Eden \& Huxham, 1996). The five steps in action research are (1) diagnosis, (2) analysis; (3) feedback; (4) action; (5) evaluation. The benefits of action research are that it is problem rather than solution focused. That is, the change agent looks objectively at the problem, and it is the problem that determines the action taken rather than the favorite solution of the change agent. Secondly, because it involves a number of employees in the process (particularly in the feedback stage), resistance to change can be reduced.

Typically, the six steps in action learning are: Problem Identification, Planning, Action, Observation, Reflection, and Implications for Practice. The observation, reflection and implications for practice steps are also components of a critical thinking paradigm. The reflection piece is often what is missing in the tumultuous, fastpaced teaching, learning, and working environments.

Problem Implications for

Identification $===\rightarrow$ Planning $===\rightarrow$ Action $===\rightarrow$ Observation $===\rightarrow$ Reflection $===\rightarrow$ Practice

\section{Figure 1 -- Action Learning}

\section{Benefits of Action Learning}

Benefits of action learning are sharing learning throughout multiple organizational levels; greater selfconfidence and self-awareness because of reflection, feedback and development of new insight; ability to ask better questions; and improved communications and teamwork Marquadt (1999).

\section{RESEARCH MODEL}

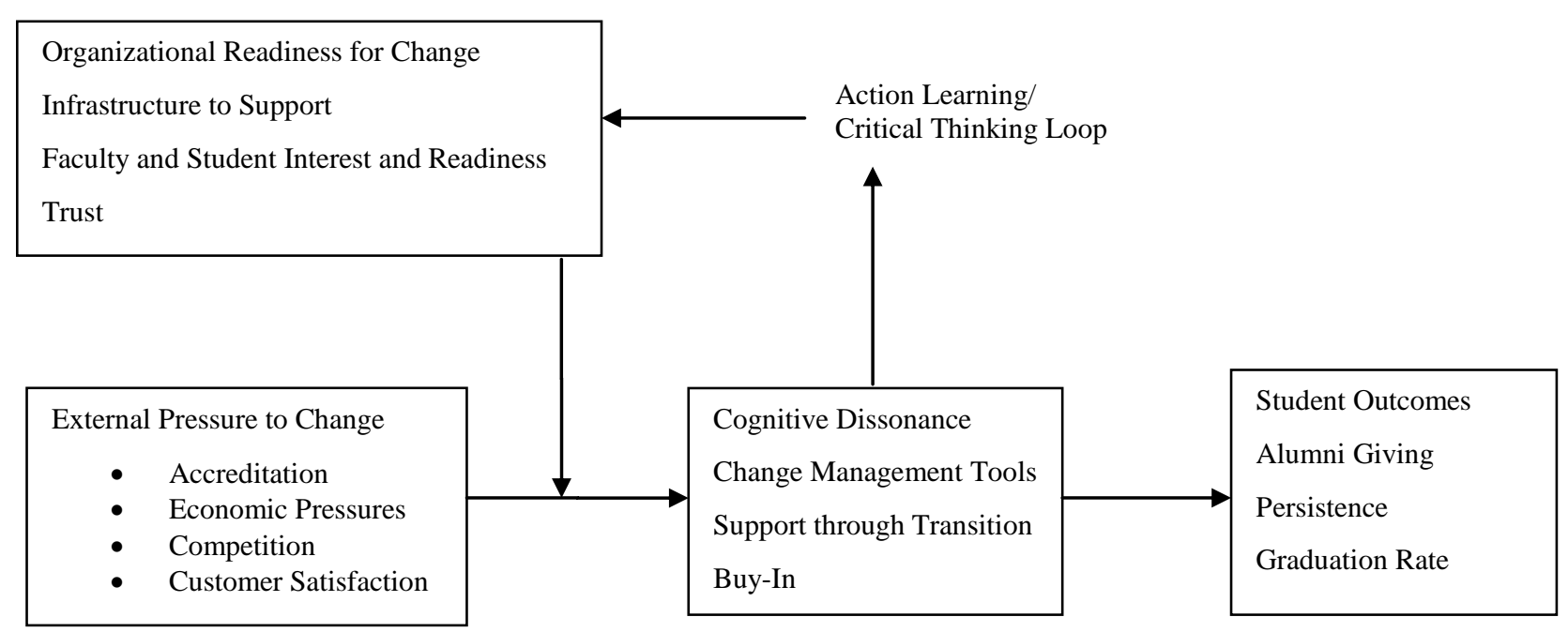




\section{RESEARCH DESIGN, METHODS, AND SAMPLE}

This research study examines the efforts of one mid-Atlantic institution to examine its curricula and to respond to its internal and external constituencies in making changes in its management curriculum in its School of Business and its general education curriculum at the University level. The institution of interest is a Master's I institution in the southeastern United States, which is part of a 17-institution university system. The students are predominantly African-American, with a good mix between first and second generation college. There are approximately 6,500 students, with a mix of $70 \%$ undergraduates and $30 \%$ graduates. Of the 350 faculty, $95 \%$ have terminal degrees.

We use an action learning and critical thinking lens to examine their processes and the things that worked well and those which did not, what they learned, and the adjustments that were made and those which should have been made in the process.

\section{Case Study 1: University Level Intervention}

The business organization, in this case, the University, wants to make a significant change in the way its students are being educated. In order to do so, it needs the support and active involvement of the faculty. This is a planned change that is intentional and goal oriented, and there are change agents that have been selected who are to act as catalysts who are responsible for managing these change activities. A key is that these change agents must be at the right level with an ability to influence the people whose support that they need to leverage these necessary changes.

In response, in part, to need to for students to become better problem solvers and critical thinkers and to remove challenges associated with silo-based learning, development of liberal arts based general education curriculum was undertaken by the Office of the Provost. Significant changes in the executive leadership team have occurred in the last 3-5 years which have resulted in a new strategic direction. There have been changes to the promotion and tenure system during this same period as well as a significant empowerment of junior faculty. An unintended result of these changes is a perceived weakening of the shared governance structure and some level of disenfranchisement by some members of the senior faculty. This research study looks at what we learned from an action learning and critical thinking perspective at the university level through these major change initiatives.

Problem Identification: Institutional need to make organizational change in general education curriculum which necessitates an organizational culture change and buy-in from all constituencies, but particularly tenure-track and tenured faculty members.

Planning: Office of the Provost integrated administrators at every level to gain buy-in from faculty and to communicate the message to faculty; utilized open forums and general faculty meetings to communicate what was going to happen and why.

Action 1: A number of administrators and junior faculty, including instructors, were involved in the initiative to identify the general education curriculum, what the components needed to be, what the categories were, how it should be launched, how classes should be considered for inclusion. As with other university-wide initiatives, in some departments, faculty were handpicked to participate; in other departments, faculty were invited to volunteer. In some cases, the same junior faculty were given high-visibility assignments which were never offered to senior faculty and about which other faculty (and high-level administrators) were unaware. A lot of energy, effort, and work was put into this effort. These change agents were charged with getting their faculty colleagues involved, gaining their input and commitment, and serving as a resource in updating them on the status of the initiative. This initiative relied heavily on technology to communicate with the general faculty but also on the department chairs and committee members to encouragement involvement and to provide information and feedback from all faculty. The general faculty was asked to include this on the agenda, and the faculty senate was updated as well. The curriculum was eventually approved and additional courses have been added. 
Action 2: A University General Education Curriculum Advising Model was developed. In this way, the university transitioned from a "prescriptive," major-focused curriculum into a more liberal one that focuses on a "flexible" complement of skill sets that make the student marketable and prepared for the workforce and graduate school. In addition, there was created an action learning experience for students and advisors in which student and advisors work together to develop a "pathway" to success. They worked together as an action learning team. There was an array of choices for the student rather than a locked-in curriculum that forced the student into rigid areas rather than allowing one to develop a myriad of interests. In addition, the student was provided a coach, who was their faculty advisor, who can provide them with advice about several majors and career advice once they have chosen a major. Throughout this process, the student is engaged — not passive in academic career choices. They are using their critical thinking skills and are questioning, making informed choices. The onus is on them for remaining engaged in the process and on the system for tracking them and providing both "head" and "heart" service to them. This has great potential to work.

Observation: Significant changes were made in areas which impacted faculty - in the promotion and tenure system and in curriculum. While the changes were inclusive, some faculty perceived them as top-down and several senior faculty may have felt disenfranchised.

Reflection: It will take the active involvement and commitment of everyone to ensure that the work that has been done that is good is enhanced; that which could be improved is; and that the university community comes together and does what is in the best interests of the students. The techniques to overcome resistance to change were not used appropriately and bridge building and healing needs to occur. Those in leadership have the savvy to make sure that that happens and that the university moves forward in positive and productive ways.

Action 3: Freshman Seminar was converted from a general "welcome to the campus" seminar to a liberal learning seminar in which freshmen could learn about a variety of topics of interest to them. The gamut of topics ranged from "Mozart is really cooking" to "Hip Hop is My Thang". This introduced students to learning in a fun, fastpaced way in a pass/fail one-credit hour course. Hopefully, this allowed them to become part of a cohort of mutual interest, encouraged them to go to class, and helped them to develop a relationship with at least one faculty member early in their college experience. All of these help to build persistence, ultimately leading to successful matriculation.

Action 4: Toastmasters provides another opportunity for students to develop their oral communication and critical thinking skills. This highly acclaimed and well developed professional program is an integral part of our students' development and gives them the freedom to determine how far they want to go in becoming accomplished speakers and leaders. Other actions needed to effect a cultural change includes offering more internships to provide hands-on, real-world experience in which students apply what they have learned in the classroom. The School of Business and Economics developed a Professional Development Center, which, coupled with the Career Services Center, enhances the students' professional image and development. There are a myriad of student organizations through which students can explore careers and interact with professionals across a broad spectrum of industries.

Another institution-led initiative is the partnership with Leadership Winston-Salem, through which faculty, staff and Honors students or Chancellors Scholars can engage in Community Action Learning Projects which lack an obvious solution and they can integrate theory and practice. Individuals are provided with opportunities for research, planning, creativity, collaboration, negotiation, etc. In addition, Action Learning Teams chosen based on variety of factors, such as "Untainted, non-experts exploring a complex problem through a fresh set of eyes... while exercising a learning discipline" (LWS Action Learning Coach Handbook, 2009). On these teams, a coach is assigned and community partners are involved.

The second case study gives an example of how each classroom can become part of the cultural change that needs to happen for the larger university change to happen. 


\section{Case Study 2: Course Level Intervention}

Students were involved in HR Concentration in preparation for a career as human resource professionals. Their curriculum is a technical one which requires expertise in a number of areas of human resource management, including employee and labor relations, compensation and benefits, performance management, occupational health and safety, employment law from an HR perspective, discrimination, staffing, training and development, mergers and acquisitions, organizational and HR strategy, leadership and the like. Students are expected to know how to think tactically for entry-level HR positions. As they learn more, through practice, about HR issues in the field, they will develop strategically and more critically about how "gray" many of the HR issues are. The purpose of the course they are in is to prepare them for their national Assurance of Learning Assessment which "certifies" them as content-ready for entrance in the profession in the 18 areas designated by assessment arm of the Society for Human Resource Management (SHRM) - Human Resource Certification Institute (HRCI). Their HR concentration was designed to meet the curriculum guidelines of this organization.

There was an error in the catalog description did not have the prerequisites correctly listed. Students were being allowed to take the capstone class with only one HR course. Two students in the class had only one HR class; 2 had 2 previous HR classes, and 10 students had 4 previous HR classes. This class in which they were jointly enrolled was both the prep class for their national Assurance of Learning Assessment and an assessment of our HR Concentration.

Problem Identification: How does one teach a capstone class for 10 students when 4 students have not had $90 \%$ of the material?

Planning: We had to move from an assessment-based, content-rich assurance of learning assessment preparation course to an action learning, critical thinking/problem solving based course. These skills would be helpful for the students as they pursued their career interests, but they would not help the students enter the field of HR for which they were matriculating. Using Bronwell's (2012) model, I determined what the critical thinking skills were that the students needed to use, hone, develop in this class and what action learning tools do I employ to get to those? (1) Identifying key definitions and concepts - if students understood what the underlying definition or concept meant, they would be able to respond to an assessment question. This was better than memorizing a definition or concept; (2) defining the central issue or problem - getting to the core issue allows them to understand the variables that impact and are impacted by what we are studying; (3) classifying information into groups - the students had to synthesize information from eight different management courses that they had taken, and it had to make sense to them; (4) recognizing patterns - they needed to begin to see how the information was fitting together, how the functional areas of HR were interconnected; (5) identifying relationships between elements using comparing and contrasting and cause and effect; and (6) formulating questions for clarification - much of what HR professionals do is knowing how to ask questions to get to the information that they needed.

Action: Students and I discussed the situation in which we now found ourselves. Those who had had three on-line only classes with me had been very excited about this first face-to-face integrative capstone class. We first discussed their observations and feelings about the boundaries for the course. They were allowed to articulate their feelings but to use respectful and HR and OB terms as they responded. We then broke into teams to come up with strategies and recommendations on how we might comply with the Dean's directives to allow the students with only 1 or 2 prior classes while preserving the integrity of the course for individuals who needed it as a capstone course.

Using the seven principles of undergraduate education developed by Chickering and Garrison (1987) (1) Encourage contacts between students and faculty - created additional office hours to stabilize the students and to ascertain where they were in thinking about HR; (2) Develop reciprocity and cooperation among students in course - asked students to form groups of 3-4 to be responsible for delivering the content; (3) Use active learning techniques such as case studies, discussion board, on-line assessments, project/workshop, and on-line blogging - the students could create whatever activities they would like to reinforce the learning for themselves and their classmates; (4) Give prompt feedback to the students - students received feedback every class period on how they were doing, via Blackboard as they shared their materials with me, and in our face-to-face interactions in my office; (5) Emphasize time on task - how long work should take - I gave time parameters on how much time they should 
spend in preparing for their sections and how long they would have in each class session to share ; (6) Communicate high expectations - I modeled what I wanted and how I wanted them to present in terms of professional presence and the use of HR language; and (7 Respect diverse talents and ways of thinking. - students were encouraged to use their creativity in sharing the 18 content areas with each other and with me. We had a schedule to meet, and we met in class each period to ensure that they were on track.

We had a sample exam from HRCI and a number of practice exams from PHR/SPHR classes with content similar to what the students would have on their exam with some application questions. They were challenged with why would this be the correct answer rather than "that"? How do you support that answer? What would make this answer a better one?

Observation: Students did not have their previous textbooks from their HR classes. Some had rented textbooks; others had never purchased them. The students who had more HR classes under their belts had less work to do in gathering information and were more motivated than the students who only had one class. Those less senior students attended class less frequently, shared less within the group, did not hold up their share of the workload with the group, and were a type of brain drain on the group. They were not able to contribute substantively to class discussion, needed things explained to them at a rudimentary level, and required more time than those preparing for their national assurance of learning assessment could afford during our scheduled class time.

Out of 28 class sessions in which student groups were scheduled to share their learning around content that they had organized, only 6 sessions of actual sharing occurred. I carried the brunt of the load for instructional content delivery in this course. There were eight courses that were tapped into for this capstone. The content for the first area that we covered took me 30 hours to organize for them. The students that had had my classes previously had a number of notes and handouts from me. I had provided them with a 3-inch 3-ring binder full of additional materials that would help them as HR professionals. I also opened my HR library to them to help them in their search, because they did not have the required SHRM national membership. Per the students, I was the only faculty member who required this, and it took 4-6 weeks for their membership to become active once they applied.

Despite these data, what happened is that HR became more real to them. We did not focus as much on the assurance of learning assessment but on tying the pieces of HR together. They began to see the connectivity of the functional areas of HR. The world of HR began to come together for them into a mosaic rather than as a hodgepodge of unconnected threads. They began to be able to ask the 5Ws and $\mathrm{H}$ questions and to understand how one area affected the next and to see the shades of gray.

When the students did engage, they came up with creative ways of presenting the material - Jeopardy, Who Wants to Be A Millionaire, and other electronic/on-line games. Creative thinking is critical thinking. They spent a great deal of time creating these tests and mnemonics for each other and enjoyed the feedback they received from one another. I was very proud of the work that they did and they effort they expended. I requested funds to pay for the students exams, since they were also an assessment of the HR program. Unfortunately, no funds were budgeted. One student actually sat for the exam, and a second scheduled her exam for June.

The students created a collage of what they learned or understand about HR and wrote a one-page paper explaining that collage. They were finally able to articulate an understanding of the field of HR. There were no longer a series of floating data points from a series of unrelated courses. They finally got "it" - Human Resource Management. They had to work with it, fight with it, fight with me, "why didn't anyone tell me about this sooner?" - they have now paid the price - an education with their degree. Go figure! Students provided me with feedback every class period, whether or not I solicited it. If they were in a bad mood from other classes, they felt free to share their negative feelings toward me. Because of the level of work this class required, I was the source of great stress for them and the level of self-study they had to do was beyond their comfort level and what "I was paid to do."

Reflection: This was an extremely difficult semester for the students. They experienced a great deal of stress in trying to learn a wealth of material that they had not been taught in or retain from previous courses. One faculty member, no matter how well intentioned or highly qualified, cannot be a program. Without the support of the departmental, school and university leadership, the program is doomed for failure. The waste of time, intellectual 
capital, and financial resources as well as the loss of goodwill and the crushing of dreams of the students (and the faculty) are incalculable long-term costs.

Implications for Practice: With each "major" initiative that the university announces and for which it wants support, it has the departmental, school and university graveyards through which it has to navigate. Contrary to what many individuals think, individuals who are disengaged are not the poor performers. They are the good performers who no longer believe - they are the casualties of war left on the battlefield, unnoticed, unsupported, while the attention was on some other thing. The good news is - while they are yet above ground and breathing, the University can win them back.

\section{CONCLUSIONS}

High-stakes change efforts require more involvement by high-level levels at the lower-levels of the organizations. Delegation to other levels of leadership is often efficient, but it may not be effective. When there is a disconnect between what the top-tier leadership is communicating and what lower levels of the organization is being told, the final outcome may not be the best result. It may be too fragile to sustain what continues to be turbulent internal and external stressors. Check-ins with the people who are most impacted by the change and the psychological impact (the transition) and providing necessary support is critical. Even the most resilient individual can only absorb a specific level of stress into one's system without having it impact one's whole life. The reflection piece is critical - what have we done, what do we need to do now to support, who have we left behind, how do we sustain this, did we do the right thing? How do we fix what was clearly wrong? What's next? How far can we go down the road if we need to redo or undo? Are we locked in?

The University went through multiple iterations of the processes to revamp the General Education curriculum, over an 18-24 month period. The advisement model associated with it also required multiple iterations. As they learned about what worked and did not work, revisions were made to their processes and to their content. Similar strategies were employed in the HR class, as well as in the development of the Professional Development Center, working with Leadership Winston Salem, and other action learning activities and tools. What is clear is that for true learning to occur there has to be a commitment to the process, regardless of the resistance and the pain associated with it. Keys to success in both environments are faculty engagement and interest, willingness to be in a continuous improvement mode, their high level of involvement and trust in the goals and the process. Student engagement, interest and willingness to be in a continuous improvement mode were also keys to success in the classroom case study. Feedback to the Faculty Member has to be handled carefully so that the Faculty Member responds positively and does not feel demoralized. Once this process is begun, others will the trust and commitment of all involved will begin to be recognized throughout the organization.

\section{AUTHOR INFORMATION}

Dr. Janice Witt Smith, SPHR, is founder and chief consultant with J.W. Smith and Associates, LLC, a human resource, leadership and organizational development and executive coaching company. She also is Professor of management at Winston-Salem State University in Winston-Salem, North Carolina. Dr. Smith consults in leadership development, team development, career development, change management, strategic planning, and human resource consulting, and issues related to workforce diversity. She is a published author whose work examines the experiences of racio-ethnic minorities and women in organizations. E-mail: jwsmithphd@nc.rr.com (Corresponding author)

Dr. Doria Kathleen Stitts is the Associate Provost and Dean University College and Life Long Learning at Winston-Salem State University. She is also the former Associate Dean and an Associate Professor of marketing in the School of Business at Winston-Salem State University. Dr. Stitts is actively involved in the life of the University and in the greater Winston Salem community. She is a sought-after speaker, has conducted a number of workshops, and has written a number of scholarly articles. E-mail: stittsd@wssu.edu 


\section{REFERENCES}

1. Audia, P.G. and Brion, S. (2007). Reluctant to Change: Self-Enhancing Responses to Diverging Performance Measures, Organizational Behavior and Human Decision Process, 102, .255-269.

2. Bartlett, J.E. (2002). Analysis of motivational orientation and learning strategies of high school business students. Business Education Forum, 56(4), 18-23.

3. Barnett, R. (2004). Learning for an unknown future. Higher Education Research and Development, 23(3), 247-260.

4. Celuch, K. and Slama, M. (1999). Teaching Critical Thinking Skills for the $21^{\text {st }}$ Century: An Advertising Principles Case, Journal of Education for Business, pp. 14-9.

5. Chickering, A.W. and Gamson, Z.F. (1987). Seven principles for good practice in undergraduate education, AAHE Bulletin, p. 3-7.

6. Eden, C. and Huxham, C. (1996). Action Research for the Study of Organizations," in S. R. Clegg, C. Hardy, and W.R Nord (eds.) Handbook of Organization Studies, London: Sage.

7. Facione, P.A. (1990) Critical thinking: A statement of expert consensus for purposes of educational assessment and instruction. Willbrae: CA: California Academic Press.

8. $\quad$ Facione, P.A. (1998). What It Is and Why It Counts. Millibrai: California Academic Press.

9. Facione, P.A. (2006). How to use the holistic critical thinking rubric. Retrieved http://insightassessment.com/pdf files/Rubric\%20HCTSR.pdf30210

10. Facione, Peter (2007). Critical thinking: What it is and why it counts. Millbrae, CA: California Academic Press.

11. Festinger, L., (1957). A Theory of Cognitive Dissonance, Stanford, CA: Stanford University Press.

12. Garrison, D.R., Anderson, T. \& Archer W. (2001). Critical thinking, cognitive presence, and computer conferencing in distance education. American Journal of Distance Education, 15(1), 7-23.

13. Khojasteh, M. \& Smith J.W. (2010). Using Technology to Teach Critical Thinking in Higher Education, Issues in Information Systems, Vol. XI, No. 2, pp. 54-65.

14. Kotter, J.P. (March-April 1995), Leading Changes: Why Transformation Efforts Fail, Harvard Business Review, pp. 59-67.

15. Kotter, J.P. (1996). Leading Change. Harvard Business School Press.

16. Kotter, J.P. and Schlesinger, L.A. (March-April 1979) Choosing Strategies for Change, Harvard Business Review, 106-114.

17. Marquadt, M. (1999). Action Learning in Action. Davies-Black Publishing, Palo Alto: CA.

18. Rippin, A., Booth, C., Bowie, S., \& Jordan, J. (2002). A complex case: Using the case study method to explore uncertainty and ambiguity in undergraduate business education. Teaching in Higher Education, 7(4), 429.

19. Robbins, S.P. \& Judge, T. (2009) Organizational Behavior, $13^{\text {th }}$ Edition, Pearson Education, Inc, Upper Saddle River, NJ, .pp. 619-20.

20. Scriven, M. and Paul, R. (2001) Defining Critical Thinking. Retrieved http://unilearning.uow.edu.au/critical/1a.html3/2/2010

21. SHRM (2007). SHRM (2007) Symposium on the Workforce Readiness of the Future U.S. Labor Pool: Critical Skills needed for the Changing Workforce. SHRM Foundation.

22. Smith, J.W. and Clark, G. (2010). Action Research in a Business Classroom - Another Lens to Examine Learning American Journal of Business Education, 3(7), 41-56.

23. Toastmasters International (2005). Critical Thinking Survey. Found in Toastmasters Competent Leadership Manual. Toastmasters International.

24. Yang, Y.T.C., Newby, T.J. \& Bill, R.L. (2005). Using Socratic questioning to promote critical thinking skills through asynchronous discussion forums in distance learning environments. The American Journal of Distance Education, 19.3), 163-181.

25. Yeh, Y. (2006). The interactive effects of personal traits and guides practice on pre-service teachers' changes in personal teaching efficacy. British Journal of Educational Technology, 37(4), 513-526. 


\section{NOTES}

